

\section{DISCLAIMER}

This report was prepared as an account of work sponsored by an agency of the United States Government. Neither the United States Government nor any agency Thereof, nor any of their employees, makes any warranty, express or implied, or assumes any legal liability or responsibility for the accuracy, completeness, or usefulness of any information, apparatus, product, or process disclosed, or represents that its use would not infringe privately owned rights. Reference herein to any specific commercial product, process, or service by trade name, trademark, manufacturer, or otherwise does not necessarily constitute or imply its endorsement, recommendation, or favoring by the United States Government or any agency thereof. The views and opinions of authors expressed herein do not necessarily state or reflect those of the United States Government or any agency thereof. 


\section{DISCLAIMER}

Portions of this document may be illegible in electronic image products. Images are produced from the best available original document. 


\section{NOTICE}

This report was prepared as an account of work sponsored by the United States Government. Neither the United States nor the U.S. ERDA, nor any of their employees, nor any of their contractors, subcontractors, or their employees, makes any warranty, express or implied, or assumes any legal liability or responsibility for the accuracy, completeness or usefulness of any information, apparatus, product or process disclosed, or represents that its use would not infringe privately owned rights.

\section{Printed in the United States of America} Available from

National Technical Information Service

U.S. Department of Commerce 5285 Port Royal Road

Sprinafield, Virqinia 22161

Price: Printed Copy $\$ 4.00$; Microfiche $\$ 2.25$ 
HEDL-TME 75-100

$U C-79 b$

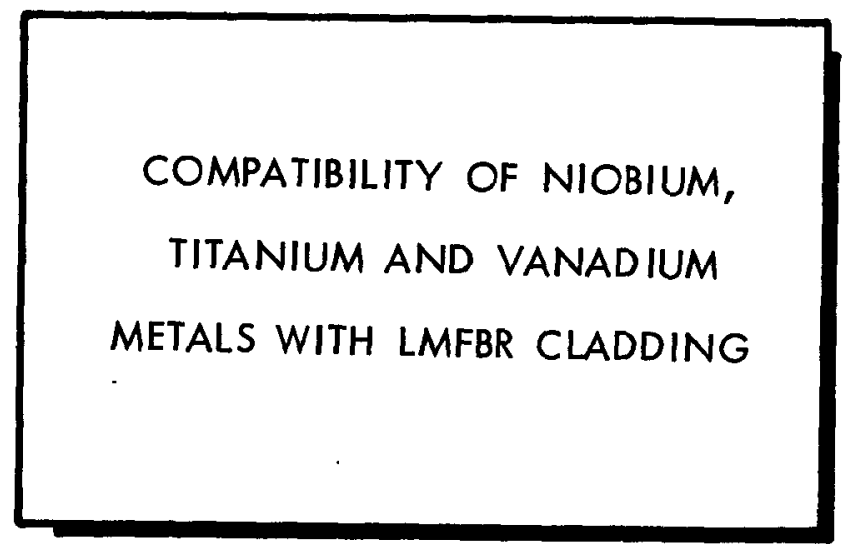

C. N. Wilson

October, 1975

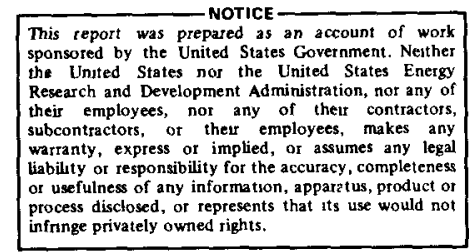

Hanford Engineering Development Laboratory

\begin{tabular}{|c|c|c|}
\hline $\begin{array}{l}\text { Operated by the } \\
\text { Westinghouse } \\
\text { Hanford Comnany }\end{array}$ & $\begin{array}{l}\text { A Subsidiary of } \\
\text { Westinghouse Electric } \\
\text { Corporation }\end{array}$ & $\begin{array}{l}\text { for the United States } \\
\text { Energy Resealreh and } \\
\text { Dovelopment Adminidtration } \\
\text { Contract No. E(45-1)2170 }\end{array}$ \\
\hline
\end{tabular}


HEDL THE 75-100

\title{
COMPATIBILITY OF NIOBIUM, TITANIUM \\ AND VANADIUM METALS WITH LMFBR CLADDING
}

\author{
C. N. Wilson
}

\begin{abstract}
A series of laboratory capsule annealing experiments were conducted to assess the compatibility of niobium, vanadium and titanium with 316 stainless steel cladding in the temperature range of $700^{\circ} \mathrm{C}$ to $800^{\circ} \mathrm{C}$. Niobium, vanadium and titanium are candidate oxygen absorber materials for control of oxygen chemistry in LMFBR fuel pins. Capsule examination indicated good compatibility between niobium and 316 stainless steel at $800^{\circ} \mathrm{C}$. Potential compatibility problems between cladding and vanadium or titanium were indicated at $800^{\circ} \mathrm{C}$ under reducing conditions. In the presence of Puo.25U0.7501.98 fuel $\left(\Delta \bar{G}_{02} \cong-160 \mathrm{kcal}\right)$ mole) no reaction was observed between vanadium or titanium and cladding at $800^{\circ} \mathrm{C}$.
\end{abstract}


0

○ 


\section{CONTENTS}

$\underline{\text { PAGE }}$

I. INTRODUCTION

II. EXPERIMENTAL PROCEDURES 2

III. RESULTS AND DISCUSSION 8

$\begin{array}{ll}\text { IV. CONCLUSIONS } & 21\end{array}$

$\begin{array}{ll}\text { V. ACKNOWLEDGEMENTS } & 21\end{array}$

VI. REFERENCES 22 


\section{FIGURES}

Number

Page

1. Capsule configurations, orientation of metal-

lographic sectioning planes are indicated as A---A.

2. Oxygen adsorber pellets used in HEDL P-23 Special Pins Test.

3. Reaction interfaces between 316 stainless steel and pressure contacted $\mathrm{Nb}, \mathrm{V}$, and $\mathrm{Ti}$ powders, $800^{\circ} \mathrm{C}$, 137 hours, $500 x$.

4. Titanium foil - 316 stainless steel interface after

137 hours at $800^{\circ} \mathrm{C}$. Etched with $10 \%$ oxal ic acid, $1000 \mathrm{x} .11$

5. SEM-EDAX traces for $\mathrm{Fe}, \mathrm{Ni}$ and $V$ across 316 stainless steel - $V$ powder interface. Extensive $\mathrm{Ni}$ diffusion is indicated by the top trace. $\left(800^{\circ} \mathrm{C}, 137\right.$ hours, $200 \mathrm{sec}$. traces.)

6. SEM-EDAX traces for $\mathrm{Cr}, \mathrm{Fe}, \mathrm{Ni}$ and $\mathrm{Ti}$ across 316 stainless steel - Ti powder interface. $\left(800^{\circ} \mathrm{C}, 137\right.$ hours, $200 \mathrm{sec}$. traces.)

7. Sections from capsules $\mathrm{Ti}-2$ and $\mathrm{Ti}-3$. Formation of a $\mathrm{Ti}$ coating on the stainless steel surface under reducing conditions at $800^{\circ} \mathrm{C}$ is shown in the lower section.

Etched with $10 \%$ oxalic acid.

8. Interface between cladding and coated fuel

pellets after 568 hours at $800^{\circ} \mathrm{C}$. (500X)

9. Equilibrium oxygen potentials of metals and mixed-oxide. (References 6 and 7)

10. Sections from capsule $\mathrm{Ti}-4$ and $\mathrm{Ti}-6,10 \%$ oxalic acid etch.

11. Sections from capsules $\mathrm{Ti}-5$ and $\mathrm{Ti}-7,10 \%$ oxalic acid etch.

TABLES

Number

Page

I. Oxygen Absorber Compatibility Capsules 


\section{INTRODUCTION}

Intergranular attack of austenitic stainless steel cladding at the fuel-cladding interface represents a potential limitation on goal exposure for FTR/LMFBR fuels. Fuel pin oxygen chemical potential $\left(\Delta \bar{G}_{02}^{*}\right)$ and fuelcladding interface temperatures appear to be the two most important parameters governing the extent of cladding attack. The cladding attack rate may be lowered by reducing the cladding operating temperature. However, with current LMFBR pin designs, a reduction in cladding temperature would have an adverse effect on overall thermal efficiency. Control of the fuel pin oxygen potential is theoretically possible by placing a material into the fuel pin to chemically buffer or getter oxygen. Irradiation tests in EBR-II (HEDL P-23 Special Pin Test and ANL 0-8 Test) have been initiated to test the effectiveness of various concepts and candidate materials proposed for the purpose of controlling oxygen chemistry in LMFBR fuel pins. Among concepts to be tested are: 1) porous metallic gettering pellets placed at the ends of the fuel column, and 2) sputtered metallic coatings on the fuel pellet surface. Niobium, titanium and vanadium metals are candidate oxygen absorber materials to be tested.

Successful application of oxygen absorber concepts to high performance LMFBR fuel pins requires that the candidate oxygen absorber materials be compatible with austenitic stainless steel cladding for extended periods at the applicable cladding inner surface temperature. Peak cladding inner surface temperatures for high performance LMFBR fuel pins are generally expected to fall into the $600^{\circ} \mathrm{C}$ to $760^{\circ} \mathrm{C}$ temperature range. Initial peak cladding temperature for FFTF is predicted at approximately $650^{\circ} \mathrm{C}$ and FFTF rated peak cladding temperature is $757^{\circ} \mathrm{C}$. (1) The peak cladding inner surface temperature predicted for the HEDL P-23 Special Pins Test in EBR-II is approximately $700^{\circ} \mathrm{C}$ at nomal power and $750^{\circ} \mathrm{C}$ at $10 \%$ overpower.

Binary phase diagrams (2) applicable to $\mathrm{Nb}$, Ti or $\mathrm{V}$ used with $\mathrm{Fe}-\mathrm{Ni}-\mathrm{Cr}$ alloys were reviewed for indications of eutectic melting in the $700^{\circ} \mathrm{C}$ to $800^{\circ} \mathrm{C}$ temperature range. For $\mathrm{Nb}$, the lowest temperature liquid phase was found in the $\mathrm{Nb}-\mathrm{Ni}$ system and occurred at $53 \% \mathrm{Nb}$ and $1175^{\circ} \mathrm{C}$. Niobium - 316 stainless steel diffusion couples have been studied and only 15 microns of 
significant interface inter-diffusion reported after 48 hours at $1100^{\circ} \mathrm{C}$.

Good chemical compatibility should therefore be expected between $\mathrm{Nb}$ and 316 stainless steel at LMFBR cladding temperatures. Binary phase diagrams indicated no apparent compatibility problems between $V$ and 316 stainless steel, with the lowest temperature liquid occurring in the $\mathrm{V}-\mathrm{Ni}$ system at $47.5 \% \mathrm{~V}$ and $1205^{\circ} \mathrm{C}$. Eutectic melting occurs in the $\mathrm{Ti}-\mathrm{Ni}$ system at $71 \% \mathrm{Ti}$ and $943^{\circ} \mathrm{C}$, and in the $\mathrm{Ti}-\mathrm{Fe}$ system at $67 \% \mathrm{Ti}$ and $1086^{\circ} \mathrm{C}$, indicating potential compatibility problems between Ti and 316 stainless steel at LMFBR cladding temperatures. However, information obtained in an initial literature survey was inclusive regarding the expected compatibility of titanium and vanadium with stainless steel at LMFBR cladding temperatures.

This report describes a series of laboratory capsule annealing experiments conducted in order to evaluate any compatibility problems between 316 stainless steel cladding and candidate oxygen gettering materials prior to in-reactor testing.

\section{EXPERIMENTAL PROCEDURES}

Sixteen capsules were assembled, annealed and examined during this investigation. The capsule test matrix is given in Table I. Four different capsule configurations (illustrated in Figure 1) were used. A11 of the compatibility capsules were sealed under argon by arc fusion welding around the end caps in an inert atmosphere glovebox. Capsules containing the metal-coated mixed-oxide fuel were encapsuled in an additional secondary capsule to provide double encapsulation. The assembled compatibility capsules were annealed in air using electrically heated furnaces. Temperature was controlled by power proportioning solid state controllers using calibrated type $K$ thermocouples. Temperature accuracy is estimate at $\pm 5^{\circ} \mathrm{C}$. Annealed capsules were prepared for metallography by drilling a hole into the capsule interior and vacuum impregnating the capsules with polyester metallographic mounting resin. The capsules were then sectioned through planes designated (A--A) in Figure 1 and polished for metallographic examination, which included SEM, electron probe, 
TABLE I

\section{OXYGEN ABSORBER COMPATIBILITY CAPSULES}

\begin{tabular}{|c|c|c|c|c|}
\hline $\begin{array}{l}\text { Capsule } \\
\text { Designation }\end{array}$ & Capsule Description & $\begin{array}{l}\text { Temp. } \\
\left({ }^{\circ} \mathrm{C}\right) \\
\end{array}$ & $\begin{array}{l}\text { Time } \\
\text { (Hours) } \\
\end{array}$ & $\begin{array}{l}\text { Approximate Reaction } \\
\text { Depth }\left(\times 10^{-3} \text { Inches }\right)\end{array}$ \\
\hline $\mathrm{Nb}$ & $\mathrm{Nb}$ powder - SS* pressure contact & 800 & 137 & 0 \\
\hline $\mathrm{Ti}$ & Ti powder - SS* pressure contact & 800 & 137 & 0.5 \\
\hline V & $V$ powder - SS* pressure contact & 800 & 137 & 0.5 \\
\hline$\overline{\mathrm{Nb}}$ & $\mathrm{Nb}$ foil - SS* pressure contact & 800 & 137 & - \\
\hline$\overline{\mathrm{Ti}}$ & Ti foil - SS* pressure contact & 800 & 137 & 0.5 \\
\hline $\bar{V}$ & $V$ foil - SS* pressure contact & 800 & 137 & - \\
\hline$T i-1$ & Porous $\mathrm{Ti}$ pellets in cladding & 800 & 89 & 0.5 \\
\hline $\mathrm{Ti}-2$ & Porous $\mathrm{Ti}$ pellets in cladding & 700 & 568 & 0 \\
\hline $\mathrm{Ti}-3$ & Porous $\mathrm{Ti}$ pellets in cladding & 800 & 568 & 1 \\
\hline$T i-V-1$ & $\mathrm{Ti} \& \mathrm{~V}$ coated fuel pellets in cladding & 800 & 89 & 0 \\
\hline $\mathrm{Ti}-\mathrm{V}-2$ & Ti \& V coated fuel pellets in cladding & 700 & 568 & 0 \\
\hline$T i-V-3$ & Ti \& V coated fuel pellets in cladding & 800 & 568 & 0 \\
\hline $\mathrm{Ti}-4$ & $316 \mathrm{SS}^{*}$ pellet on $\mathrm{Ti}$ Dynapack pellet & 700 & 71 & 0 \\
\hline $\mathrm{Ti}-5$ & 316 SS* pellet on Ti Dynapack pellet & 800 & 71 & 0.5 \\
\hline $\mathrm{Ti}-6$ & $316 \mathrm{SS}^{*}$ pellet on Ti Dynapack pellet & 700 & 568 & 0 \\
\hline $\mathrm{Ti}-7$ & 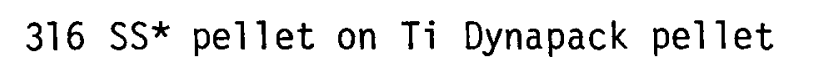 & 800 & 568 & 1.0 \\
\hline
\end{tabular}

*SS abbreviation for stainless steel. 
and electrolytic etching. Capsules containing metal-coated mixed-oxide fuel were sectioned, mounted, and examined in a plutonium metallography glovebox.

\section{A. Capsules with Pressure Contacted Powder or Foil}

In the initial investigation six capsules were assembled to give pressure contact between niobium, titanium and vanadium powders, or metal foils and 316 stainless steel capsule components. Capsules designated $\mathrm{Nb}, \mathrm{Ti}$ and $\mathrm{V}$ contained niobium, titanium or vanadium powders in the minus 200 to 500 mesh size range. Capsules $\overline{\mathrm{Nb}}, \overline{\mathrm{Ti}}$, and $\bar{V}$ contained niobium, titanium and vanadium foil. The metal powders and foils were loaded into the capsules in an argon inert atmosphere glovebox. The $3 / 8 \times 16$ threads per inch end bolts were then installed and torqued to 20 foot-pounds to provide pressure contact. The capsules were sealed by arc fusion of the capsule to the bolt under argon. The six sealed capsules were then annealed at $800^{\circ} \mathrm{C}$ for 137 hours.

The initial six capsules were designed to give extreme conditions of fine reactive powder or foil in pressure contact with stainless steel at a temperature above the maximum in-reactor cladding inner surface temperature. No interaction between the candiate oxygen absorber materials and stainless steel under these conditions would have indicated satisfactory compatibility and the study could have been terminated. However, results from the initial capsules indicated that further tests should be conducted to test porous $\mathrm{Ti}$ oxygen-gettering pellets and $\mathrm{Ti}$ and $\mathrm{V}$ sputter-coated mixed-oxide fuel for compatibility with 316 stainless steel cladding.

\section{B. Capsules with Porous Ti Pellets in Cladding}

In capsules $T i-1, T i-2$ and $T i-3$ porous titanium pellets were placed in $31620 \%$ cold worked split cladding halves. The porous titanium pellets used were prepared by Battelle-Northwest Laboratories using a Dynapack powder metallurgy process and are shown in Figure 2 . Contact pressure between porous pellets and the cladding was due only to the pellet weight. The pellet diameter was less than the cladding I.D., providing a single narrow region of axial contact between titanium and the 


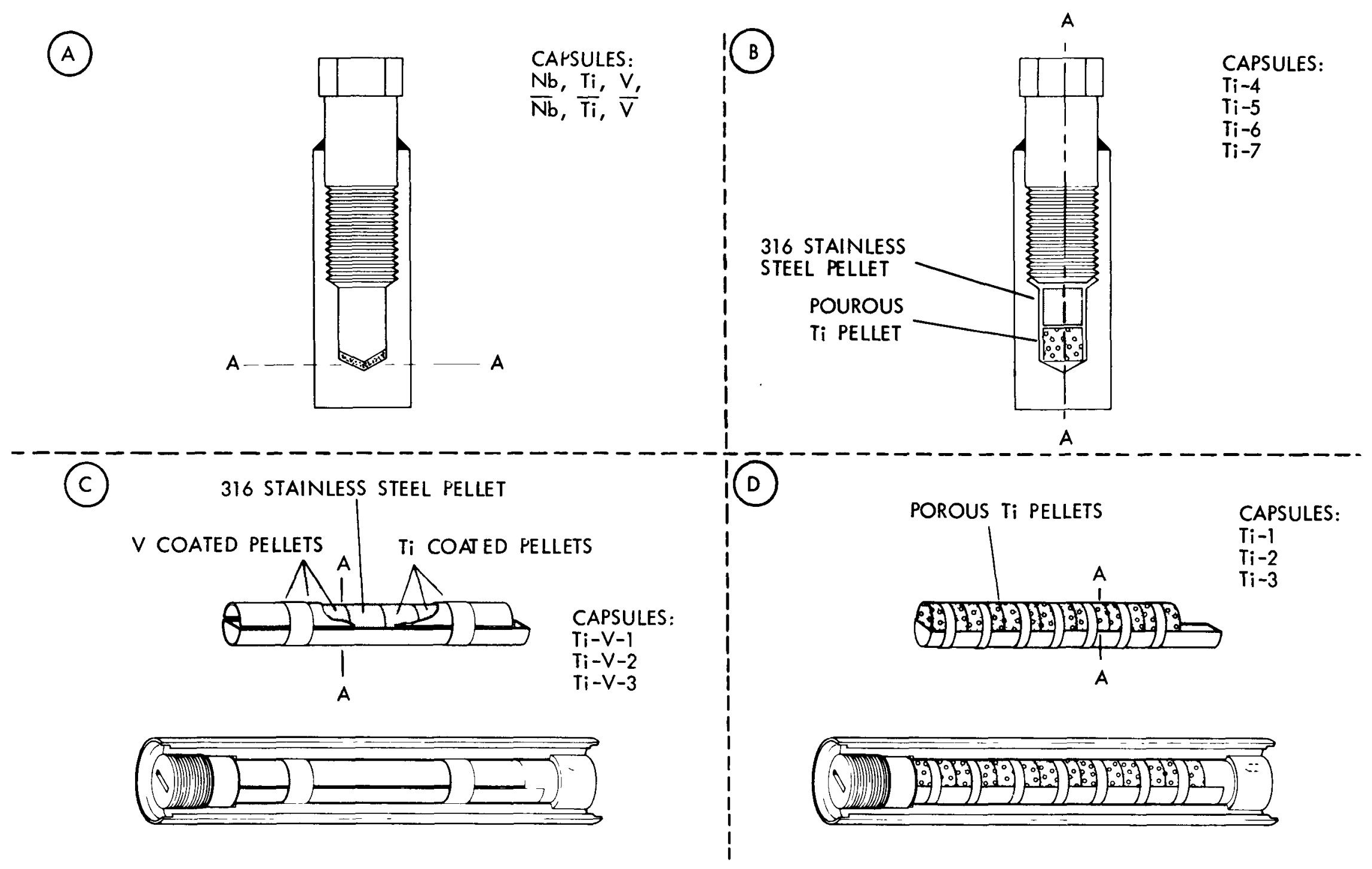

FIGURE 1. Capsule Configurations, Orientation of Metallographic Sectioning Planes are Indicated as A---A. 
cladding. Several serial sections (parallel to A---A Figure 1D) were examined metallographically. Two interface regions showing titanium-cladding interaction received additional examination using SEM equipped with energy dispersive $X$-ray flourescence analysis capabilities (SEM-EDAX).

C. Capsules with Coated Fuel Pellets

HEDL prepared mixed-oxide fuel pellets $\left(\mathrm{Pu}_{0.25} \mathrm{U}_{0.75^{0}} \mathrm{O}_{1.93}\right)$ were sputter-coated with titanium and vanadium for use in P-23 Special Pins Test in EBR-II. (4) Approximately ten microns of titanium or vanadium metal was deposited on circumferential surfaces of the fuel pellets. Capsules $T i-V-1, T i-V-2$ and $T i-V-3$ contained three of the titanium coated fuel pellets and three of the vanadium coated fuel pellets banded between two split cladding halves. Titanium and vanadium coated fuel pellets were separated by a 316 stainless steel pellet. The cladding halves were made from oversized cladding to provide a narrow axial region of fuel-cladding contact for the length of the capsule. The pellet-cladding assemblies were double encapsulated in stainless steel capsules.

After annealing, several serial sections (parallel to plane A-A in Figure IC) were cut from each impregnated pellet-cladding assembly so as to give a section through each pellet. After initial metallographic examination, each specimen was ground down an additional $0.5 \mathrm{~mm}$ and repolished to provide several additional section planes for examination. This process was repeated a third time for each section from capsule Ti-V-3. Sections from capsule Ti-V-3 were also examined by electron microprobe analysis.

D. Capsules with Planar Contact Interface

Capsules Ti-4 through Ti-7 were prepared to provide data on titanium-cladding reactions at two times and temperatures, with other conditions identical, to obtain information on Ti-cladding reaction kinetics. In these capsules, 316 stainless steel pellets were placed on top of porous titanium pellets to form an interface. Contact pressure was determined by the weight of the stainless steel pellets $(20.5 \mathrm{gm})$ on a circular interface 0.190 inches $(4.83 \mathrm{~mm})$ in diameter. Depths of reaction 

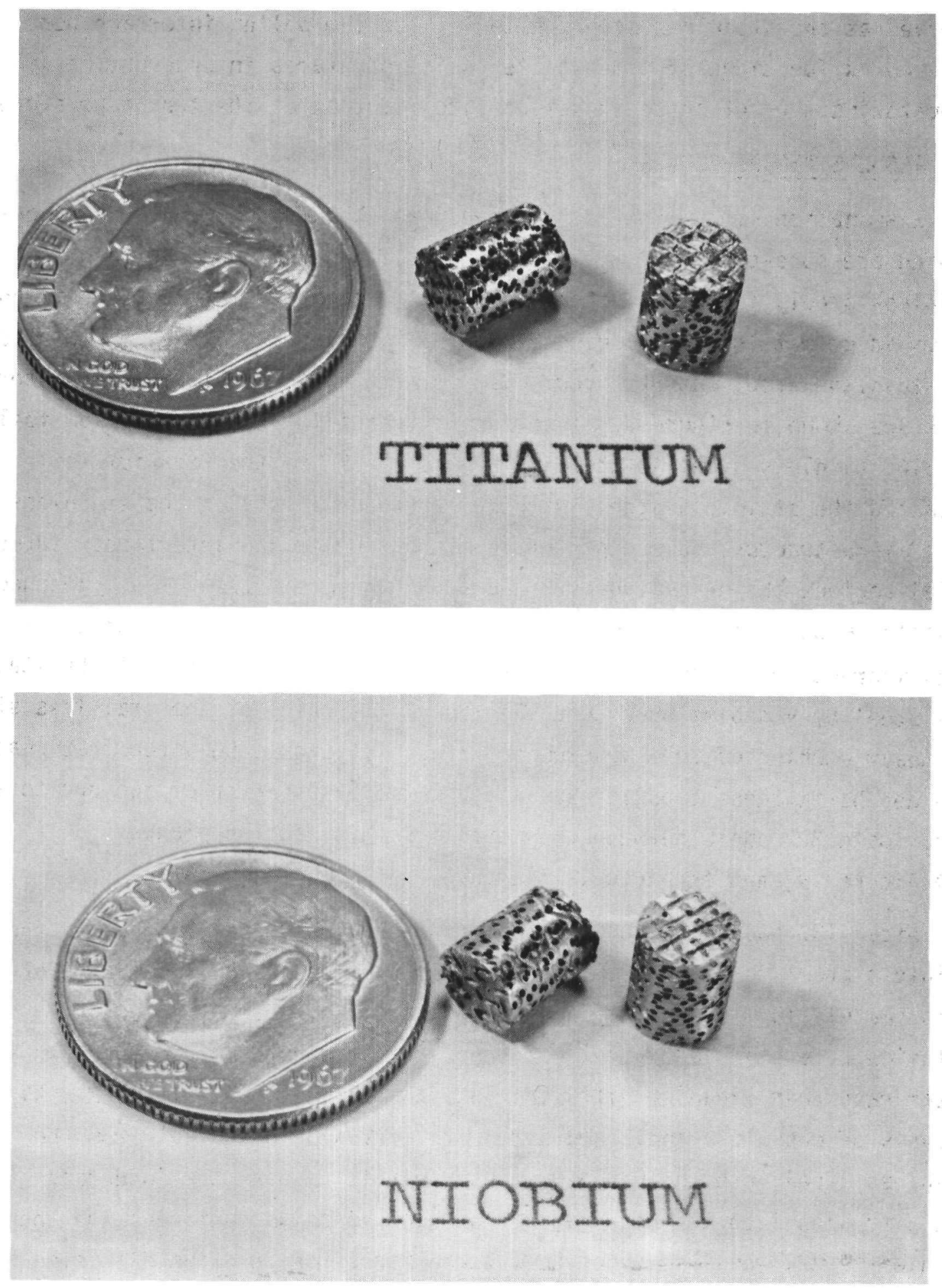

FIGURE 2. Oxygen Absorber Pellets Used in HEDL P-23 Special Pins Test. 
observed at the stainless steel pellet - titanium pellet interface were measured as functions of time at the two temperatures in order to derive an approximate reaction depth versus time relation at the two temperatures.

\section{RESULTS AND DISCUSSION}

Examination of the initial six capsules (Nb, Ti, $V, \overline{\mathrm{Nb}}, \overline{\mathrm{Ti}}, \overline{\mathrm{V}})$, containing pressure-contacted metal powder (or foil) interfaced with 316 stainless steel, indicated potential compatibility problems between titanium and vanadium metals and cladding at $800^{\circ} \mathrm{C}$. No reaction between niobium and 316 stainless steel was observed. Powder metal-316 stainless steel interfaces are shown in Figure 3. Interface interaction between titanium foiT and 316 stainless steel is shown in Figure 4 . Where the titanium foil contacted the stainless steel, etching revealed effects on the stainless steel microstructure to a depth of 10 microns below the interface. Interfacial regions shown in Figures 3 and 4 have been electrolytically etched ( 5 volts, $5 \mathrm{sec}$.) in a 10\% oxalic acid solution to reveal the stainless steel microstructure near the interface. Cathodic protection of the stainless steel by vanadium precluded electrolytic etching of the stainless steel and heavy etching of the vanadium occurred. It should be noted that reaction depths in these capsules are exaggerated by a factor of two due to the approximate $30^{\circ}$ angle between the metallographic section planes (A-A Figure 1A) and the actual interface.

After 137 hours at $800^{\circ} \mathrm{C}$, vanadium powder particles sintered to the stainless steel surface. Porosity in the stainless steel to a depth of approximately 13 microns indicated a Kirkendall effect, (5) in which diffusion of a stainless steel component into the vanadium occurred at a faster rate than vanadium diffusion into the stainless steel. SEM-EDAX analysis of capsule $V$ indicated extensive diffusion of nickel from the stainless steel into the vanadium powder particles near the interface. Iron diffusion into the neck regions between vanadium particles and the stainless steel was also observed. Beam traces for chromium diffusion behavior were inconclusive due to overlapping of chromium $K$-alpha and vanadium K-beta X-ray energies. Chromium K-beta emission showed poor signal-to-noise ratio and could not be used for chromium analysis. 
Diffusion of vanadium into the stainless steel occurred to a depth of 13 microns corresponding to the 13 micron layer of porosity and nickel depletion. SEM-EDAX traces for elements $\mathrm{Fe}, \mathrm{Ni}$ and $\mathrm{V}$ are shown in Figure 5.

Neck formation and the initial stages of sintering were observed between titanium powder particles after 137 hours at $800^{\circ} \mathrm{C}$. Particles which interfaced with the stainless steel coalesced into a continuous layer averaging about 15 microns in thickness. Between the outer reaction layer and the stainless steel a band averaging 5 microns thick occurred which was heavily etched by oxalic acid. SEM-EDAX traces $(0.5 \mu / \mathrm{sec}$.) for elements $\mathrm{Cr}, \mathrm{Fe}, \mathrm{Ni}$ and $\mathrm{Ti}$ across the interface region are shown in Figure 6. The outer reaction layer contained titanium, nickel and iron and a small amount of chromium. The appearance of the interfacial region suggested the possibility of eutectic melting. However, the compositional inhomogeneity of the outer layer would suggest that a continuous liquid phase did not exist. A melting eutectic occurs in the $\mathrm{Ni}-\mathrm{Ti}$ system at $943^{\circ} \mathrm{C}$ and 71 weight per cent titanium. Melting in the four-phase $\mathrm{Fe}-\mathrm{Ni}-\mathrm{Cr}-\mathrm{Ti}$ system would be expected below $943^{\circ} \mathrm{C}$, and $800^{\circ} \mathrm{C}$ is likely to be near the eutectic melting temperature.

Since the initial capsule tests indicated potential cladding compatibility problems with candidate titanium and vanadium oxygen absorber concepts, additional capsules were fabricated using porous titanium pellets and titanium and vanadium coated fuel pellets in contact with cladding in order to more accurately simulate conditions in the P-23 special pins irradiation test.

Examination of capsules $T i-1, T i-2$ and $T i-3$ indicated reaction occurred between porous titanium absorber pellets and cladding at $800^{\circ} \mathrm{C}$ in an argon atmosphere. After 568 hours at $800^{\circ} \mathrm{C}$ reaction zones penetrating to a maximum depth of 30 microns into the cladding were observed. No reaction was observed at $700^{\circ} \mathrm{C}$. Metallographic sections through $700^{\circ} \mathrm{C}$ and $800^{\circ} \mathrm{C}$ titanium - cladding interfaces are shown in Figure 7. Points of physical contact at porous titanium pellet - stainless steel interfaces were not observed during metallographic examination of $700^{\circ} \mathrm{C}$ capsules. Mechanical forces during mounting and sectioning most likely caused separation at 

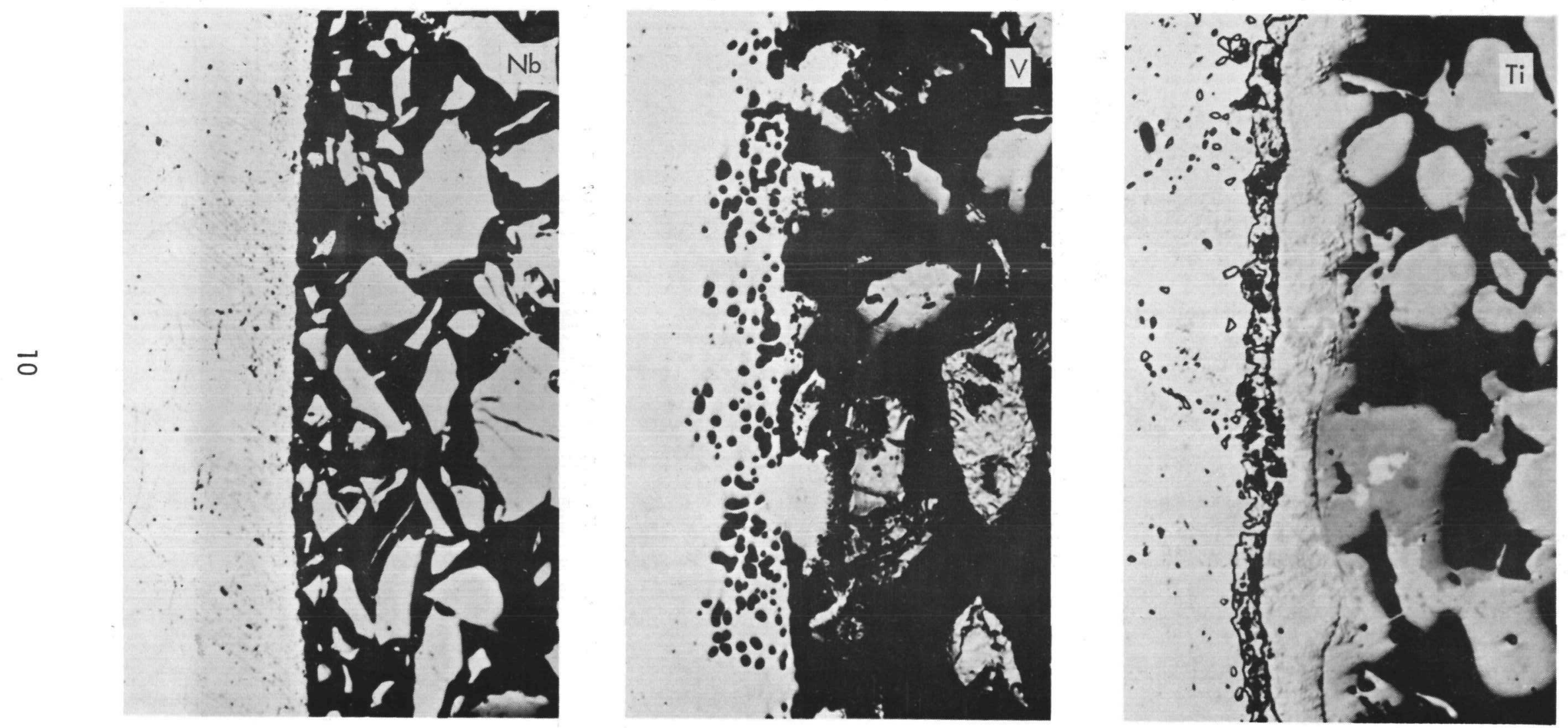

FIGURE 3. Reaction Interfaces Between 316 Stainless Steel and Pressure-Contacted Nb, V, and I Powders, $300^{\circ} \mathrm{C}, 137$ Hours, 500X. 


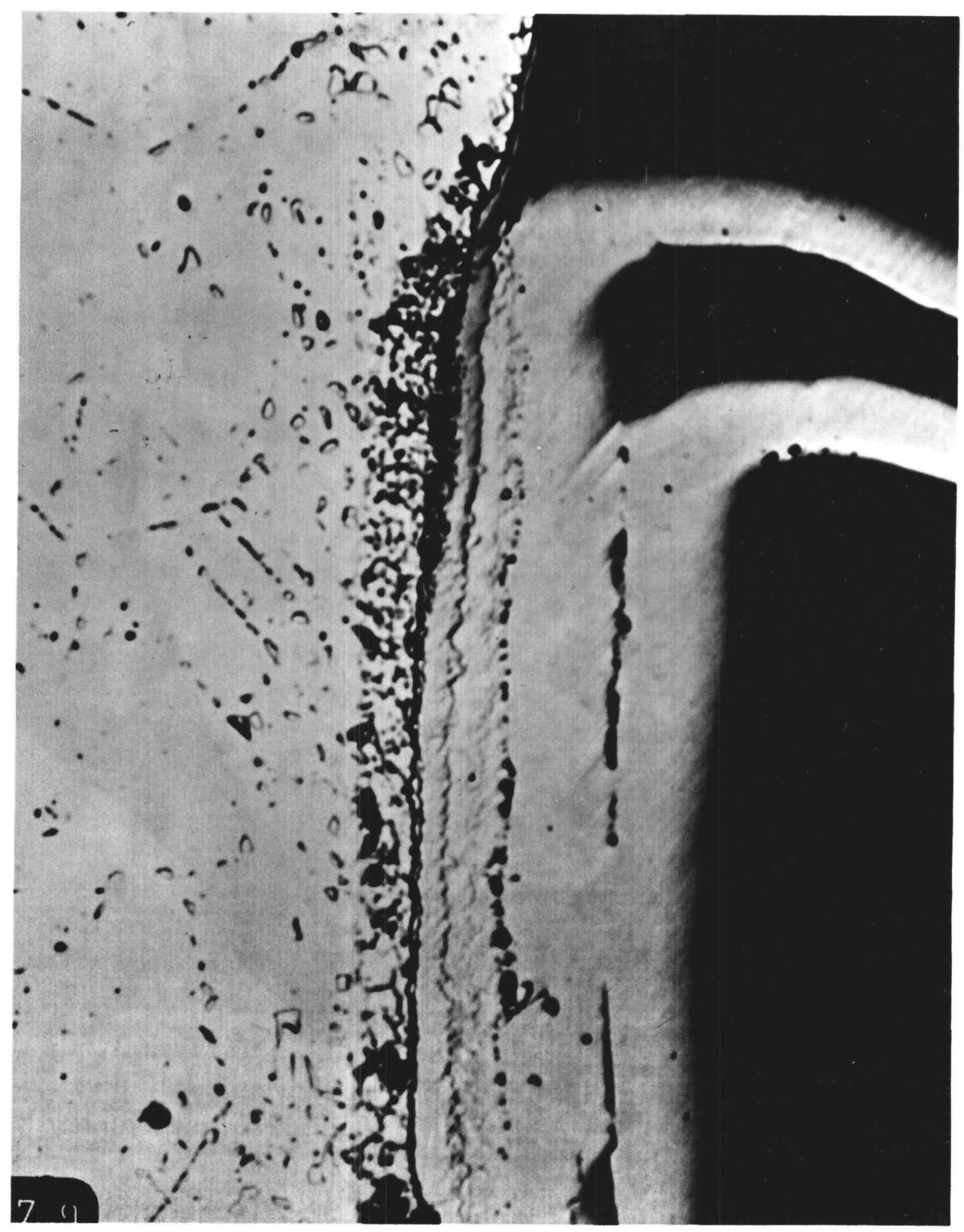

FIGURE 4. Titanium Foil - 316 Stainless Steel Interface after 137 Hours at $800^{\circ} \mathrm{C}$. Etched with $10 \%$ 0xalic Acid, 1000X. 

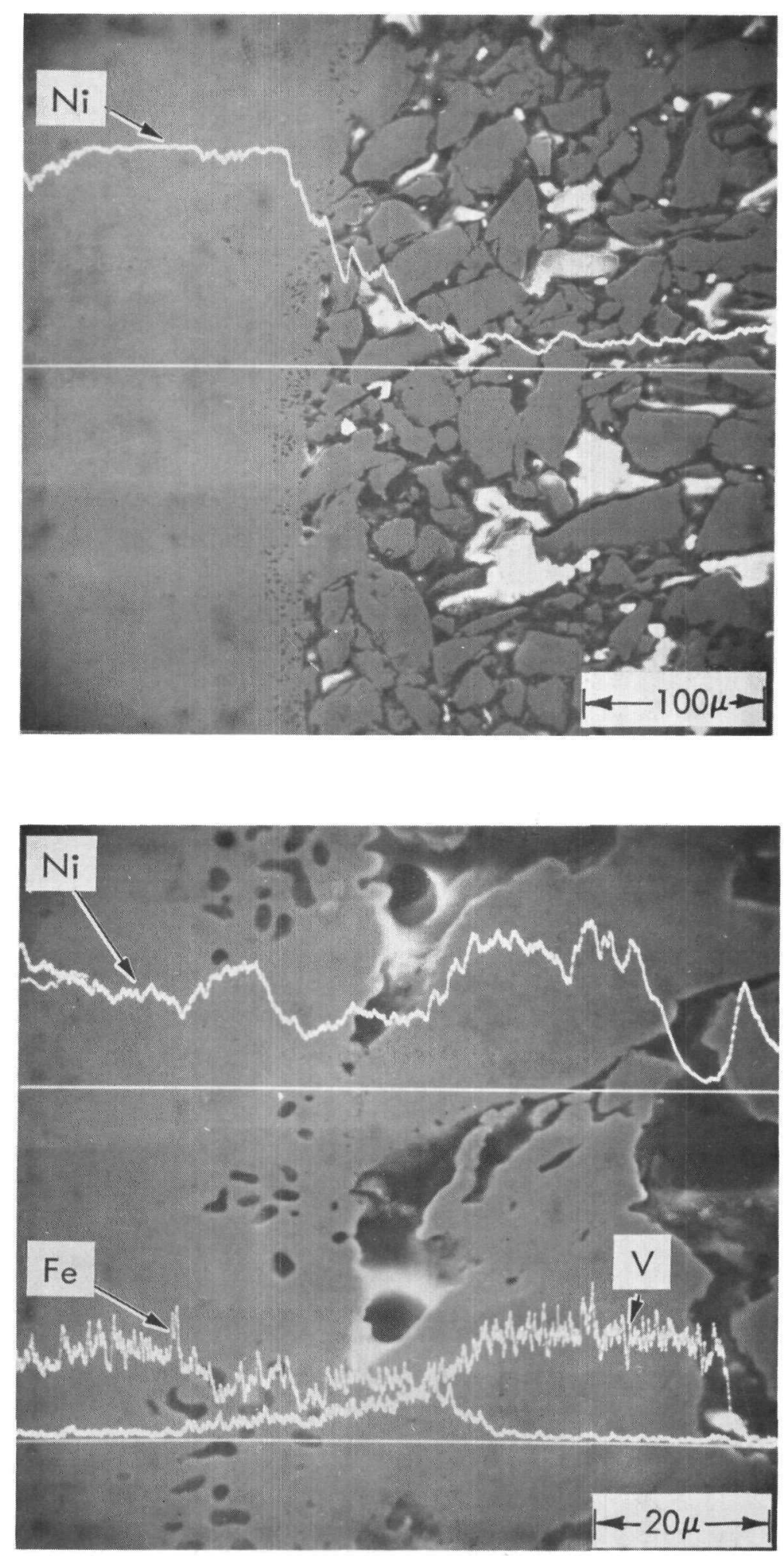

FIGURE 5. SEM-EDAX Traces for $\mathrm{Fe}, \mathrm{Ni}$ and $\mathrm{V}$ Across 316 Stainless Steel - V Powder Interface. Extensive $\mathrm{Ni}$ Diffusion is Indicated by the Top Trace. $\left(800^{\circ} \mathrm{C}, 137\right.$ Hours, $200 \mathrm{Sec}$. Traces.) 


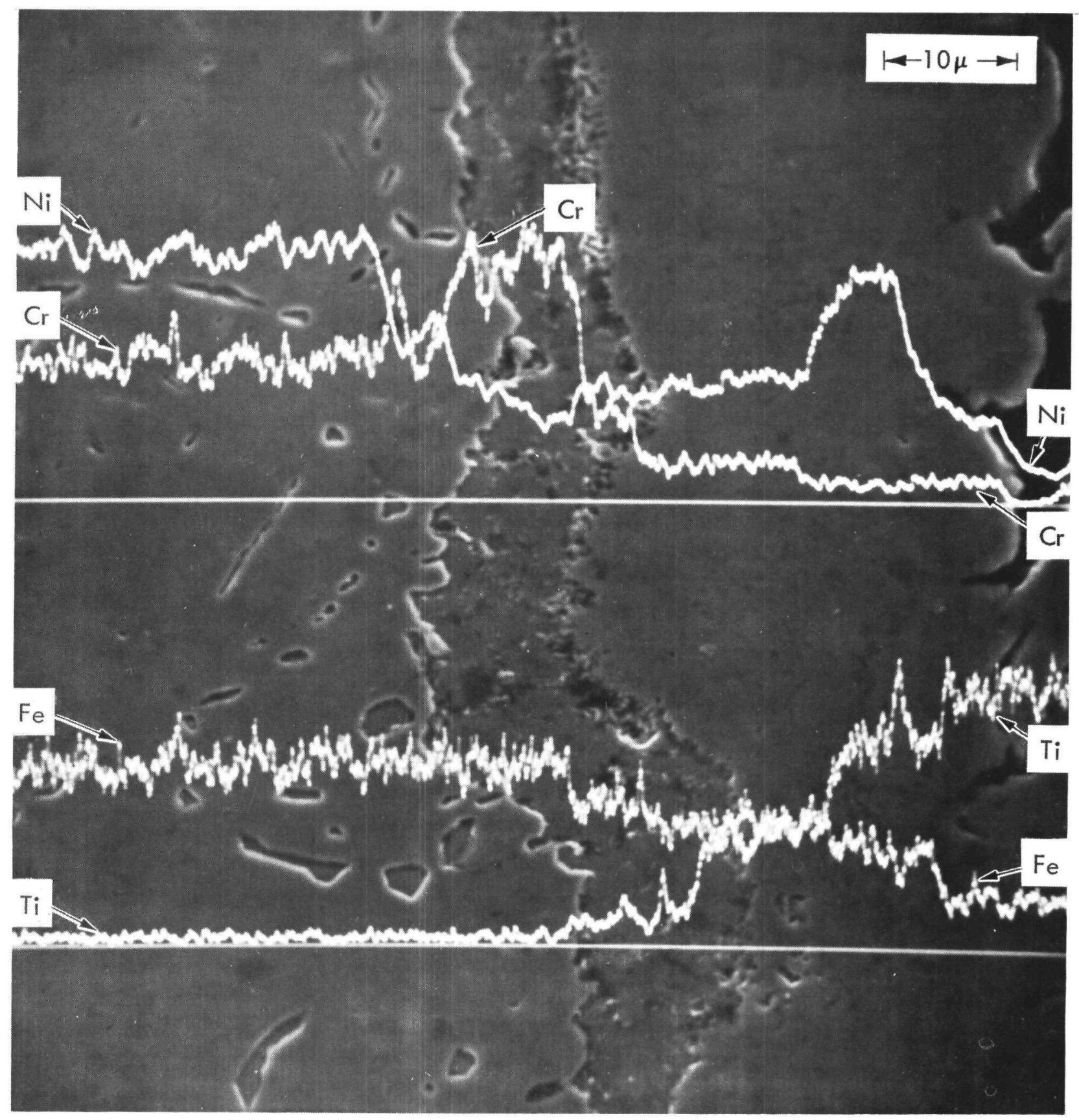

FIGURE 6. SEM-EDAX Traces for $\mathrm{Cr}, \mathrm{Fe}, \mathrm{Ni}$ and $\mathrm{Ti}$ Across 316 Stainless Steel - Ti Powder Interface. $\left(800^{\circ} \mathrm{C}, 137\right.$ Hours, $200 \mathrm{Sec}$. Traces.) 


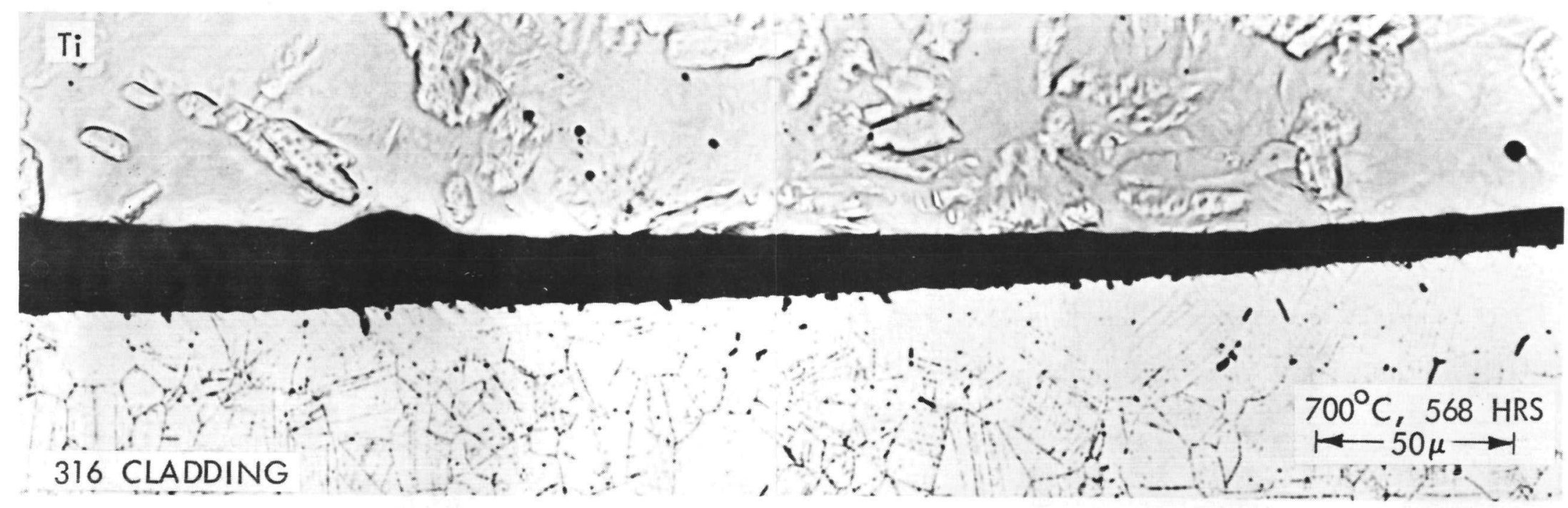

$\vec{p}$

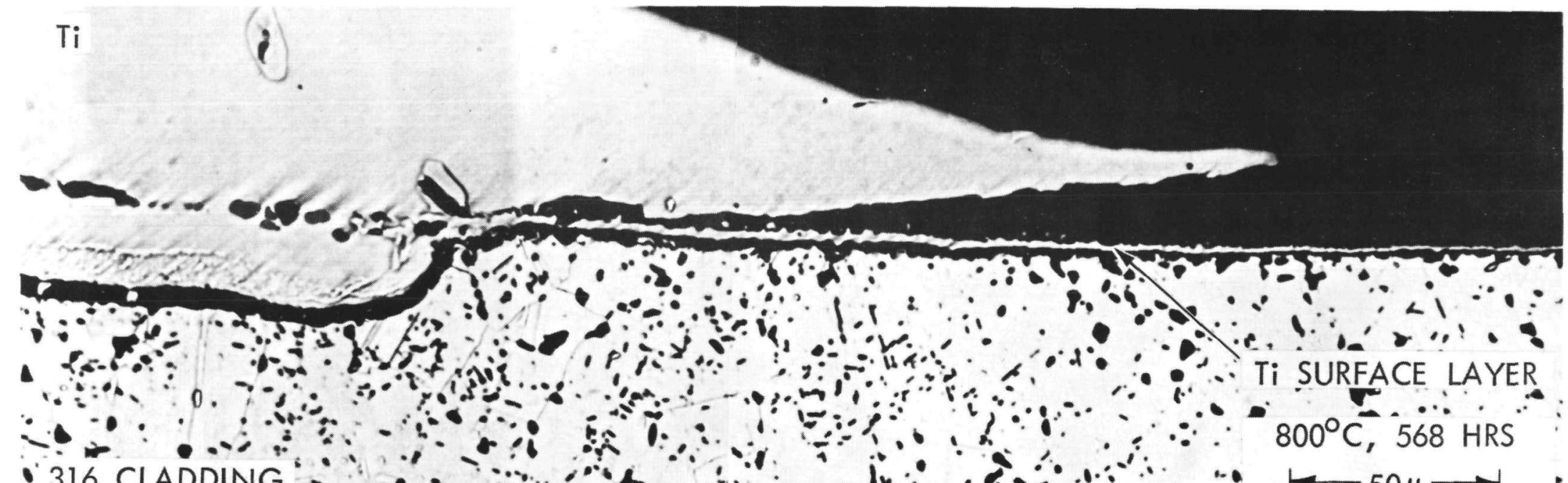

FIGURE 7. Sections from Capsules Ti-2 and Ti-3. Formation of a Ti Coating on the Stainless Steel Surface Under Reducing Conditions at $800^{\circ} \mathrm{C}$ is Shown in the Lower Section. Etched with $10 \%$ Oxalic Acid. 
interfaces which were not bonded by interfacial reaction. Localized interface contact during annealing was assumed as a result of capsule design and assembly conditions. Porous titanium pellets were centerless ground around their circumference and end ground. Capsule components were cleaned prior to assembly and care was taken to el iminate dust particles from the interface during assembly. All metallographic sections from porous titanium pellet-containing capsules annealed at $800^{\circ} \mathrm{C}$ showed regions of interface reaction. No regions of reaction were observed in identical capsules annealed at $700^{\circ} \mathrm{C}$.

No reaction between cladding and vanadium or titanium coated mixedoxide fuel was observed after 568 hours at $800^{\circ} \mathrm{C}$. Metallographic sections from capsuTe Ti-V-3 are shown in Figure 8 . The reduced reactivity of titanium and vanadium toward 316 stainless steel in the presence of mixedoxide fuel may be explained by the difference in oxygen chemical potential in fuel-containing and non-fuel-containing capsules. In the non-fuel capsules, the oxygen inventory was limited to the oxygen contained in the oxide passive layers at metal surfaces. At $800^{\circ} \mathrm{C}$, both vanadium and titanium would be reducing to the cladding (chromium oxide) passive iayer. Once the cladding surface had been reduced at the cladding-vanadium or cladding-titanium interface, a defect occurrence in the vanadium or titanium oxide surface layer could allow metallic bonding to the cladding and reaction to occur. If oxygen equilibrium was approached in the non-fuel capsules, the oxygen potential would be determined by the most reducing surface in the capsule. Under these conditions the healing of any defect in oxide passive layers would be slow and reaction at points of contact between oxygen absorber pellets and cladding could occur. The equilibrium oxygen potential of titanium, vanadium and chromium oxide-metal couples, ${ }^{(6)}$ along with Woodley's data ${ }^{(7)}$ on $25 \% \mathrm{PuO}_{2}$ mixed-oxide oxygen potentials, are plotted as a function of temperature in Figure 9. Mixed-oxide fuel at an $0 / \mathrm{M}$ of 1.98 and $800^{\circ} \mathrm{C}$ is oxidizing to titanium and should provide sufficient oxygen activity to maintain the integrity of an oxide passive layer at the cladding-absorber interface. Since fuel $0 / M$ and $\Delta \bar{G}_{\mathrm{O}_{2}}$ at the fuel-cladding 


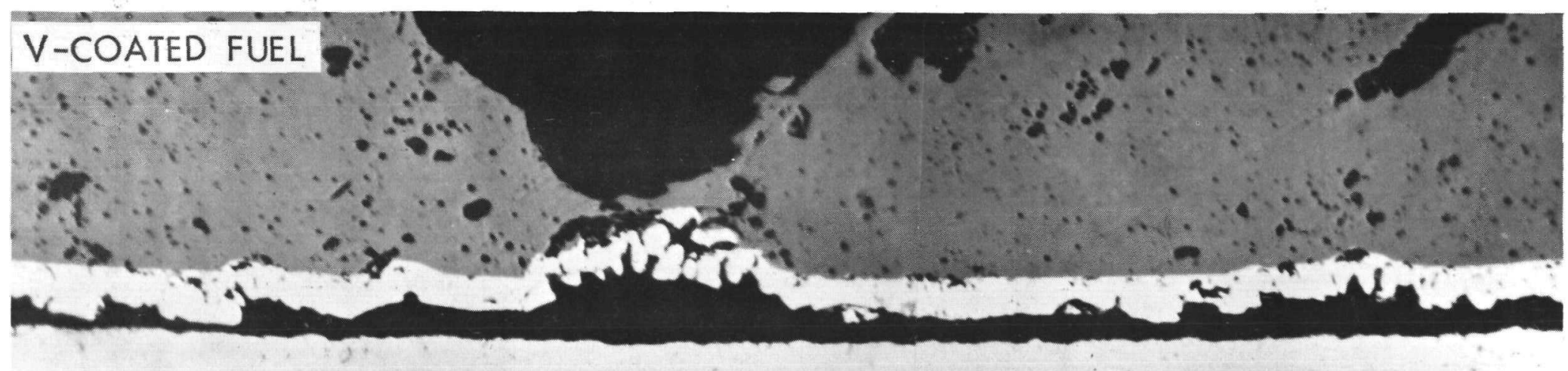

CLADDING

ने

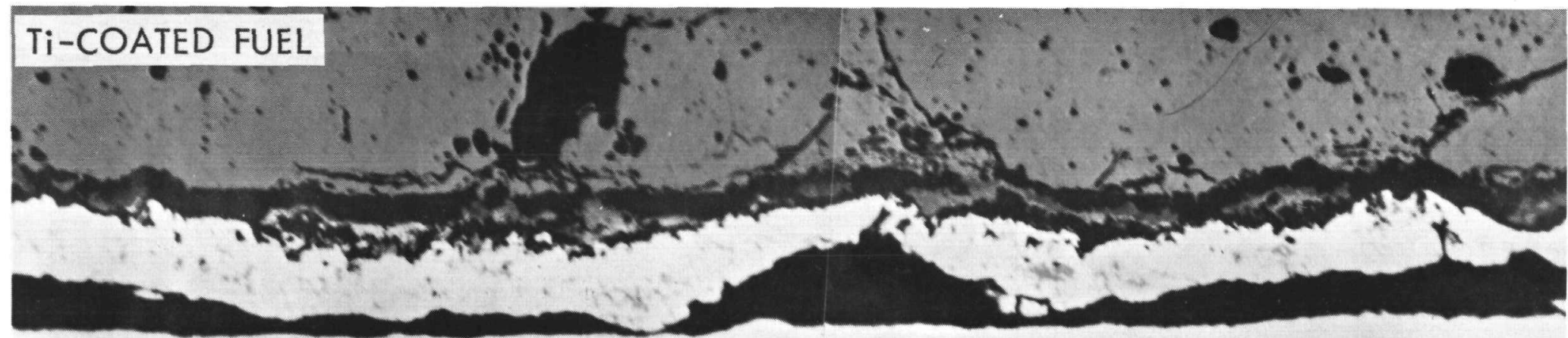

CLADDING

FIGURE 8. Interface Between Cladding and Coated Fuel Pellets After 568 Hours at $800^{\circ} \mathrm{C}$. (500X) 
interface tend to increase with burn-up, the probability of reaction between oxygen absorbers and cladding would be expected to be reduced with burn-up.

Mixed-oxide fuel at an $0 / \mathrm{M}$ of 1.98 and $800^{\circ} \mathrm{C}$ is slightly reducing to vanadium oxide. However, the $\Delta \bar{G}_{02}$ difference between vanadium and $0 / M=$ 1.98 fuel at $800^{\circ} \mathrm{C}$ is only about $4 \mathrm{kcal} / \mathrm{mole}_{2}$, and the vanadium-cladding interface was probably not sufficiently reduced to allow metallic bonding across the interface in the capsules containing vanadium coated fuel. Vanadium-cladding reaction may be possible in fuel pins containing initially low $0 / M$ fuel and operated at the highest predicted LMFBR cladding temperatures. However, the effect of initially low $0 / M$ fuel on $\Delta \bar{G}_{02}$ at the fuelcladding interface should tend to be compensated for by oxygen redistribution along the radial temperature gradient in an operating fuel pin.

Additional effects of capsule oxygen potential were observed in all non-fuel titanium containing capsules annealed at $800^{\circ} \mathrm{C}$. In these capsules, a surface layer of titanium was observed coating the stainless steel surface in regions not contacted by titanium. The titanium layer is shown as a bright ribbon extending along the stainless steel surface in Figure 7. The presence of the titanium ribbons indicates either increased titanium vapor pressure or increased titanium surface diffusion under reducing conditions.

Capsules $\mathrm{Ti}-4$ through $\mathrm{Ti}-7$ indicated that under reducing conditions the titanium-cladding reaction rate in terms of cladding penetration decreases with time. Interfaces from capsules $\mathrm{Ti}-4$ through $\mathrm{Ti}-7$ are shown in Figures 10 and 11 . An eight-fold increase in annealing time at $800^{\circ} \mathrm{C}$ caused a two-fold increase in reaction penetration depth. Using the relationship of depth of reaction proportional to the cube root of time, 639 days would be required for a reaction depth of 0.003 inches $(75 \mu)$ at $800^{\circ} \mathrm{C}$ based on reaction depths observed in capsules Ti-5 and Ti-7. This would provide adequate time for irradiation testing of the HEDL P-23 Special Pins containing porous titanium absorber pellets. Furthermore, cladding penetration due to reaction with titanium absorber pellets in a typical LMFBR application should be less than that observed in the $800^{\circ} \mathrm{C}$ 


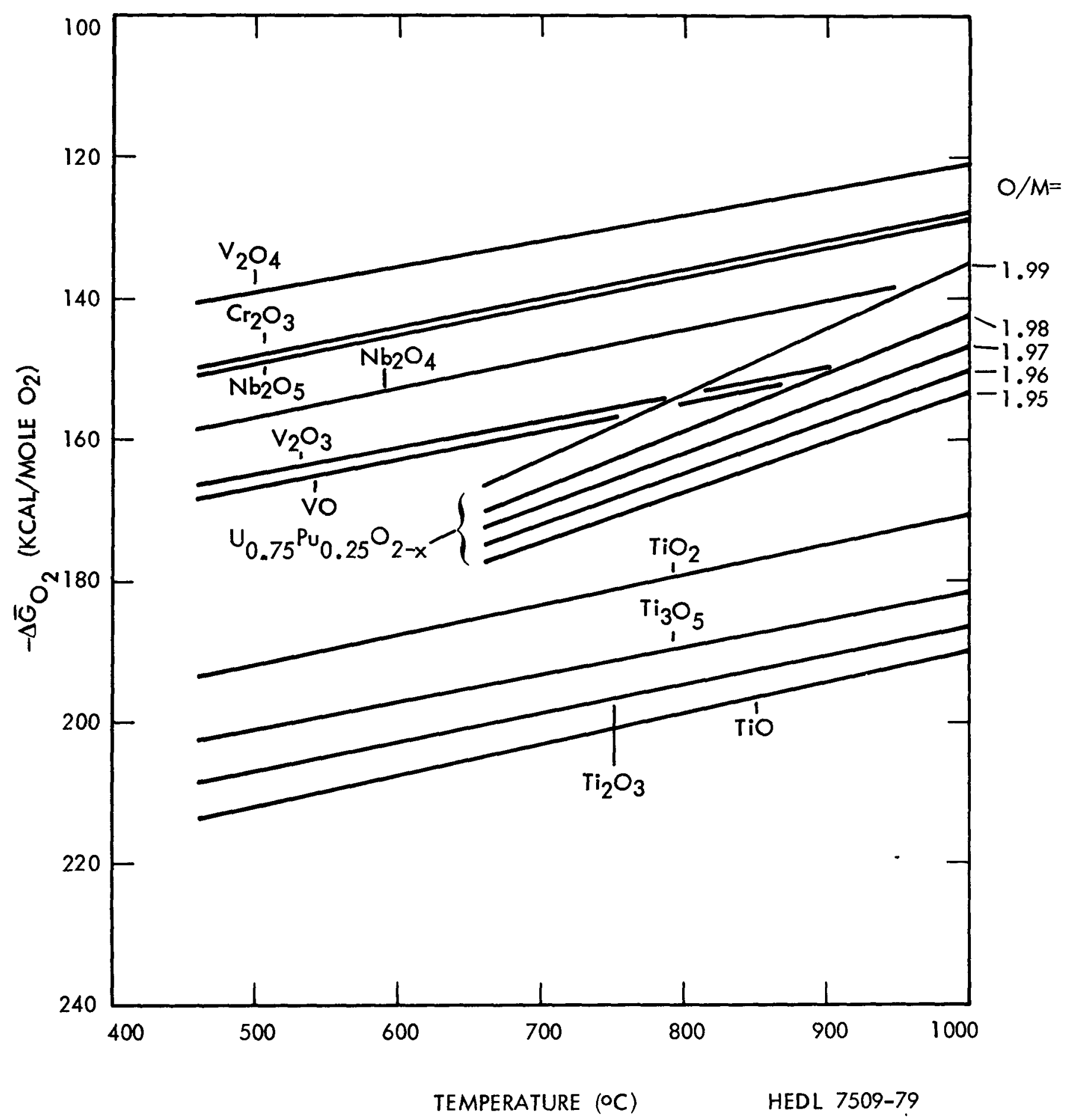

FIGURE 9. Equilibrium Oxygen Potentials of Metals and Mixed-0xide Fuel. (References 6 and 7 ) 


\section{○}
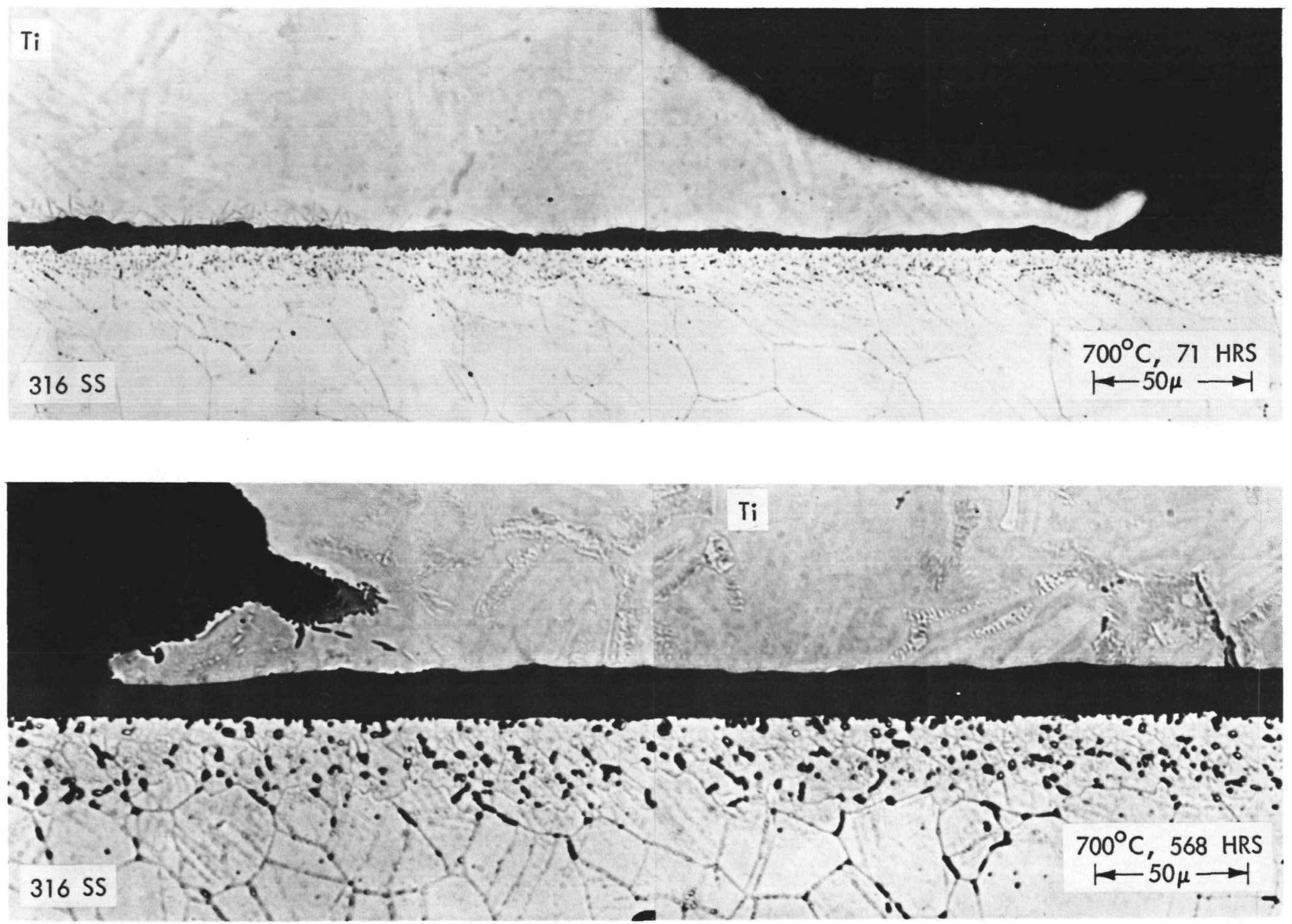

FIGURE 10. Sections from Capsule Ti-4 and Ti-6, 10\% 0xalic Acid Etch. 

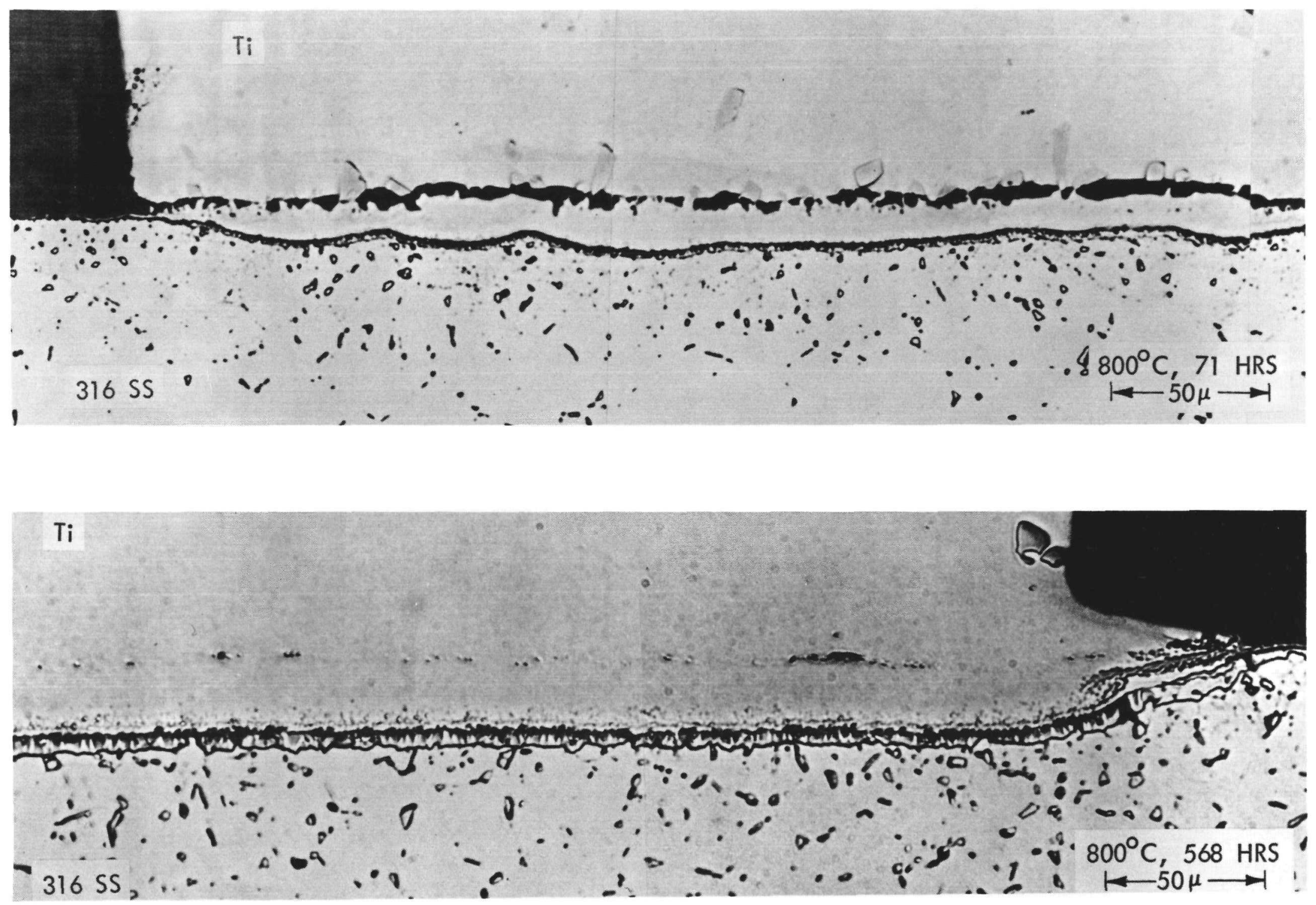

FIGURE 11. Sections from Capsules Ti-5 and Ti-7, 10\% 0xalic Acid Etch. 
capsules in this investigation. Predicted peak cladding temperatures in LMFBR high performance fuel pins will be less than $800^{\circ} \mathrm{C}$ and will probably be in the $650^{\circ}$ to $750^{\circ} \mathrm{C}$ temperature range. Oxidation of the titanium pellets and reaction with fission products at the titanium-cladding interface should further reduce titanium-cladding reaction. Absorber pellet reaction with oxygen and fission products is also expected to reduce cladding-vanadium reaction rates. While some reaction between cladding and titanium and vanadium is possible at the highest predicted LMFBR cladding inner surface temperatures, the extent of reaction, and the effects of fission products and irradiation damage cannot be predicted quantitatively. Experience from initial irradiated fuel pins containing these oxygen absorber materials should provide the basis for more detailed predictions.

IV. CONCLUSIONS

Based on data obtained from analysis of laboratory compatibility test capsules, niobium, titanium and vanadium candidate oxygen absorber concepts are expected to show adequate compatibility with 316 cladding for irradiation testing of these materials in fuel pins. The compatibility rating, in order of decreasing compatibility potential, would be niobium, vanadium, titanium. At $800^{\circ} \mathrm{C}$ the compatibility of $316 \mathrm{cladding}$ with titanium and vanadium is considered marginal, with the presence or absence of reaction dependent upon a fuel pin oxygen chemical potential adequate for maintenance of an oxide layer at the oxygen absorber-cladding interface. For cladding inner surface temperatures less than $700^{\circ} \mathrm{C}$, no compatibility problems between 316 cladding and vanadium or titanium coated fuel or porous titanium pellets is foreseen.

\section{ACKNOWLEDGEMENTS}

The author wishes to acknowledge and thank the following persons for their assistance: A. Schmidt (University of Washignton) for SEM-EDAX assistance, V. A. Harmon and G. L. Jones for laboratory assistance; and R. E. Woodley, E. T. Weber and L. A. Blackburn for technical review of this report. This work was supported under ERDA-RRD 189 Number FF026/GTE, Task $A$. 


\section{REFERENCES}

1. C. M. Cox, "FFTF Fuel Pin Design Basis and Performance," paper presented at European Nuclear Conference, Paris, April 21-25, 1975.

2. Metals Handbook, 8th Edition, Vol. 8, AMS Publication, 1973.

3. L. S. Brinks, R. E. Seebold, J. Nuclear Materials, Vol. 3, No. 4 pp 249-259, 1961.

4. HEDL Quarterly Technical Report, July-September 1974, HEDL-TME 74-3 Vol. 1 .

5. P. G. Shewmon, Diffusion in Solids, pp 116-117, McGraw Hill Book Company, 1963.

6. U. S. Bureau of Mines, Bulletin 542, 1954.

7. R. E. Woodley, "Equilibrium 0xygen Potential - Composition Rela-

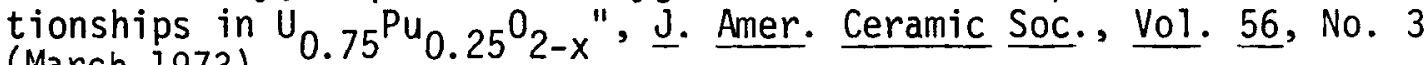
(March 1973). 


\section{DISTRIBUTION}

UC-79 Basic (188)

UC-79b (43)

ERDA/RL (2)

A.G. Fremling

R.M. Poteat

FFTF/PO (5)

R.L. Ferguson

ERDA/RRD-HQ

Director

HEDL (38)

L.D. BTackburn

G.A. Last

A.G. Blasewitz

L.A. Lawrence

C.A. Burgess

T.T. Claudson

R.D. Leggett

W.E. Roake

C.M. Cox

O.D. Slagle

E.T. Weber

R.E. Dahl

J.W. Weber

R.L. Gibby

J.E. Hanson

C.N. Wilson

C.A. Hinman

R.E. Woodley

J.J. Holmes

J.M. Yatabe

C.W. Hunter

Central Records and Files (10)

M.K. Korenko

Publications Services

(2)

J.J. Laidler 